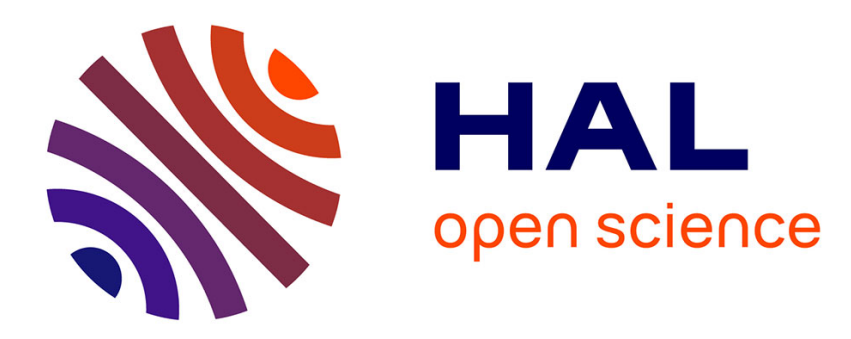

\title{
The Valuation of Decision and Individual Welfare: A Humean Approach
}

\author{
André Lapidus
}

\section{To cite this version:}

André Lapidus. The Valuation of Decision and Individual Welfare: A Humean Approach. European Journal of the History of Economic Thought, 2010, 17 (1), pp.1-28. hal-00344868

\section{HAL Id: hal-00344868 \\ https://hal-paris1.archives-ouvertes.fr/hal-00344868}

Submitted on 5 Dec 2008

HAL is a multi-disciplinary open access archive for the deposit and dissemination of scientific research documents, whether they are published or not. The documents may come from teaching and research institutions in France or abroad, or from public or private research centers.
L'archive ouverte pluridisciplinaire $\mathbf{H A L}$, est destinée au dépôt et à la diffusion de documents scientifiques de niveau recherche, publiés ou non, émanant des établissements d'enseignement et de recherche français ou étrangers, des laboratoires publics ou privés. 


\section{INTRODUCTION}

A canonical theme in social choice theory concerns the manner in which a potential social preorder can be based upon individual preferences. Nonetheless, while there is an abundance of literature placing emphasis on the conditions of existence and the forms of the relation between the two instances, individual and social, little interest is shown in the identification of what, for an individual, contributes to the determination of social well-being. This underestimation is linked to a widespread habit of thought, at least among those who adopt a welfarist approach. They assume there to be an implicit equivalence, for the same individual, between decisional valuation and the valuation of individual welfare: if our decision is the choice of a greater element over a set of opportunity of choice, according to a preference relation, this choice in turn corresponds to the greatest valuation of our individual welfare, such as it is reflected in social welfare.

It seems hardly worth mentioning that this confusion of decision with valuation of welfare might be inherited from classical utilitarianism; the same pleasure and pain which, if one believes Jeremy Bentham (1789, p. 1), are imposed upon us by nature, govern on the one hand our decisions and, on the other, themselves constitute the measure of what we would call today our individual welfare. However, while the work of David Hume was a particular

\footnotetext{
* PHARE, Université Paris I Panthéon-Sorbonne - 106-112, bd de l'Hôpital - 75647 Paris Cedex 13 - France. Email : lapidus@univ-paris1.fr. I benefited from comments and suggestions provided by many colleagues and by an anonymous referee of this Journal. As always, Marc-Arthur Diaye's comments were particularly insightful and helpful. The usual caveat remains, of course. Financial support from the French ANR contract 3LB is also gratefully acknowledged.
} 
source of inspiration for Bentham, his writings do encourage a reconsideration of this confusion. Some passages in Book II of the Treatise of Human Nature (1739-40), as well as the Enquiry Concerning the Principles of Morals (1751), or the Dissertation on the Passions (1757), and some of the Essays (1777) suggest that for Hume, that which prompts a decision and its valuation - 'desire' and the 'force of the idea of pleasure' - is distinguished from the valuation of individual welfare - first of all 'interest', and then 'happiness'.

Those passages in Hume's writings that can be interpreted in terms of a decision theory (\$ 1) link it to an estimation of the idea of pleasure based upon a belief in the realisation of an impression of pleasure. Here we privilege beliefs in relation to impressions occurring at different dates, which lead one to submit decisional valuation to the degree of violence of the passions of the individual concerned. The calculus of welfare ( $\S 2$ ) is first introduced in the Treatise as a way of abstracting from the distorting effects of beliefs that lead us to underestimate future pleasures. The resultant interest appears to conform to a decisional valuation made under the influence of a calm passion. But the second Enquiry (Hume 1751) suggests a different mode of evaluating individual welfare, that of the greatest happiness, which some of the Essays suggest can be linked to the prevalence of calm passions. Interest and happiness thus appear to be two competing valuations in response to two distinct objects: interest is that modest objective which, pursued with calm passion, leads us along a passionate trajectory whose outcome is our greater happiness.

\section{Decisional Valuation and the Measurement of Pleasure}

\subsection{Decision and the Process of the Passions}

An earlier article (Diaye and Lapidus 2005a) showed that, for Hume, a decision appears as the result of a transformation in the passions, mobilising in turn what he calls "indirect passions" (pride, humility, love, and hatred; see Hume 1739-40, II, pp. 332-3 and 1757, p. 144) and 'direct passions' (joy, grief, hope, fear, desire, aversion, and volition; see Hume 1739-40, II, p. 438 , and 1757 , p. 139), without the description of this process calling for anything other than a mere reference to the role played by pleasure and pain. Not that these are subordinate for Hume, pleasure and pain are the cause of direct passions ${ }^{1}$ and the product of indirect

\footnotetext{
1 "By direct passions", writes Hume, "I understand such as arise immediately from good or evil, from pain or pleasure" (Hume 1739-40, II, p. 276). And so that no ambiguity might exist over Hume's hedonistic perspective. "good" and "evil" are explicitly presented later in the text as synonyms for "pleasure" and "pain" (Ibid., p. 439). The relation between direct passions and decision theory is discussed in Diaye and Lapidus (2005a, pp. 93-6) and Lapidus (2000). For a more general analysis Chs. 1, 2, and 5 of Páll Árdal (1966) cannot be ignored, and the reader might refer with profit to J.-P. Cléro (1985).
} 
passions. ${ }^{2}$ But once this point is accepted - that is to say, once attention is directed to the apparatus of the passions - although passions are strictly speaking modalities of pleasure and pain, that is, ways of living on them, they seem self-sufficient enough, so that analysis can be restricted to the way in which they are generated from each other, prompting either desire or aversion, hence will and finally, action.

The elements forming a theory of decision derived from Hume's writings thus appear as an aspect of his theory of the passions. This latter is generally known to be founded upon an impassioned dynamic in which reason plays only a subordinate role (Hume 1739-40, II, pp. 415-7). The impassioned dynamic leads the passions to converge towards either desire or aversion, which would today be acknowledged as the expression of a general or a contextual preference, that is, as a binary relation $\mathrm{R}$ or $\mathrm{R}_{\mathrm{S}}$ respectively defined over a reference choice set $\mathrm{X}$, or over a subset $\mathrm{S}$ of $\mathrm{X}$, corresponding to a context of choice (also called in an alternative terminology the "opportunity set" or "budget"). In the same way, where desire and aversion are focussed in the will that immediately precedes action, it is possible to see here an expression of what is usually called a decisive (that is, nonempty) function of choice $\mathrm{C}(\mathrm{S})$ of a subset $\mathrm{F}$ of the set of the nonempty parts of $\mathrm{X}$ (the domain of choice) to the set of the nonempty parts of $\mathrm{X} .{ }^{3}$ The evolution of the set of reference of choice $\mathrm{X}$, of the domain of choice $\mathrm{F}$, of contextual preference $\mathrm{R}_{\mathrm{S}}$ and of general preference $\mathrm{R}$ as well as of the choice function $\mathrm{C}(\mathrm{S})$, might be viewed as the outcome of a revision process, conforming to rather loose conditions which illustrate the properties of what Hume calls the "double association" or "double relation" of impressions and ideas. ${ }^{4}$ The algorithm D-PROC (Diaye and Lapidus 2005a, pp. 103-5) which describes this evolution is capable of generating rationality, as defined in the two following senses (the second being stronger than the first), which seem to capture the intuitive significance of the word in the standard theory of choice in a context of certainty:

1. The rationality of the choice function (Diaye and Lapidus 2005a, p. 105, Proposition 1), i.e. the possibility to infer from choice a preference relation compatible with it. In such a case, what an agent chooses when he is confronted with alternative

\footnotetext{
${ }^{2}$ See for example, in the Treatise, the explanation of the pleasure derived from the indirect passion of pride (Hume 1739-40, II, pp. 290-1).

${ }^{3}$ For a discussion of the assimilation made here between desire, aversion and preferences on the one hand, and will and choice on the other, see Diaye and Lapidus 2005a, pp.94-5 and 98-9 and 2005b, pp. 120-1.

4 "The present theory of the passions depends entirely on the double relations of sentiments and ideas, and the mutual assistance, which these relations lend to each other" (Hume 1757, p. 158). This principle was analysed in detail in Book II of the Treatise (Hume 1739-40, II, pp. 282-4), recalled on several occasions (for instance, Hume 1739-40, II, pp. 332-3) and then again in Book III (Hume 1739-40, III, pp. 574).
} 
contexts of choice $\mathrm{S}$, might be viewed as the choice of what he prefers. More formally, that means that the choice function $\mathrm{C}(\mathrm{S})$ can be rationalised by a binary relation $\mathrm{R}$ on $\mathrm{X}$, so that $\forall \mathrm{S} \in \mathrm{F}$, the set of optimal elements on $\mathrm{S}$ relatively to $\mathrm{R}$ being $\mathrm{G}(\mathrm{S}, \mathrm{R})=\{x \in \mathrm{S}: x \mathrm{R} y, \forall y \in \mathrm{S}\}, \mathrm{C}(\mathrm{S})=\mathrm{G}(\mathrm{S}, \mathrm{R})$.

2. The rationality of the preference relation (Diaye and Lapidus 2005a, p. 106, Proposition 2), according to which preference is a complete preorder. In other words, $\mathrm{R}$ will be a complete $(\forall x, y \in \mathrm{X}, x \mathrm{R} y$ or $y \mathrm{R} x)$ and transitive $(\forall x, y, z \in \mathrm{X}, x \mathrm{R} y$ and $y \mathrm{R} z \Rightarrow x \mathrm{R} z$ ) binary relation.

One of the distinctive features of this approach is that rationality is not assumed as a prerequisite from the beginning of the choice process. The commonly recognised properties of a choice function and of a preference relation thus appear to be a possible result of D-PROC, conditional upon a stabilisation of the passions that terminates the process of revision of preferences. In other words, when we arrive at a particular emotional stability, our preferences no longer need be reviewed; they are then as rational as our choices. This means that we have the possibility of exploring the decision process within a Humean perspective without resorting more specifically to the concept of pleasure.

\subsection{Pleasure as an Impression and as an Idea}

As a result, it might seem paradoxical to maintain that Hume was a hedonist. However, Hume's hedonism is more sophisticated than the Benthamite utilitarianism we are used to: on the one hand, pleasure is determining in the formation of our desire and our will - our preferences and our choices; on the other hand, while it is relatively easy here to discern a measure, it would not be evident whether this was a measure associated with preferences, that is to say, a decisional valuation.

The determining role of pleasure in the functioning of the passions is stated in Book I of the Treatise where the influence of beliefs is discussed, then taken up again in different ways in the two other books (Hume 1739-40, I, p. 118; II, p. 438; III, p. 574). The 1757 text is no different to the Treatise (for a comparison of the Treatise and the Dissertation on this point see Lapidus 2000, pp. 34-7) in stating that "[a]11 good or evil ["in other words, pain and pleasure" (Hume 1739-40, II: 439)], whence-ever it arises, produces various passions and affections, according to the light in which it is surveyed" (Hume 1757, p. 139).

That this role is not extended into a valuation associated with desire is less intuitive. This is firstly because we have today a Benthamite perspective, in which the measurement of pleasure (the felicific calculus) is also a decisional indicator. Consequently, and more technically, because we know that if a complete preorder of preference R (as produced by DPROC) is continuous (or, more generally, given appropriate properties of the set $\mathrm{X}$ over which it is defined), it can be represented by a real-valued function $u($.$) that can be called$ 
"utility function", defined up to an increasing monotonous transformation, such that $\forall \mathrm{x}, \mathrm{y} \in$ $\mathrm{X}, \mathrm{xRy} \Leftrightarrow \mathrm{u}(\mathrm{x}) \geq \mathrm{u}(\mathrm{y})$. Now, it should be stressed that Hume's approach is just the opposite, and starts from a real-valued function to reach a complete preorder. After all, it seems natural for an eighteenth century writer to provide an intuitive expression of what could be considered a "pleasure function" $\mathrm{p}(\mathrm{x})$, which was called upon to play a part symmetrical to that of the utility function, but representing the preference preorder since it generates this preorder, instead of being engendered by it. From this point of view, Hume wrongfoots both the Benthamite tradition and the familiar procedures of decision theory.

The reasons for these differences relate to the mental processes that Hume describes in order to explain the manner in which pleasure determines desire and the will. Whereas pleasure is at first an impression of sensation, it intervenes in the passions as an idea of pleasure, whose "force and vivacity" 5 creates what Hume calls a belief, transferred to the desire and will which precede action. Of course, this should make us careful when considering the terminological options available to the author of the Treatise as they appear to us in retrospect: "belief" is here is used in a technical sense and has little to do with ordinary language, and is also distinct from the meaning usually given to it in decision theory, as a probability associated with the realisation of a given state of the world. Above all, reference to belief leads to emphasis being placed on the reasons which will lead an idea of pleasure to express with greater or lesser force the correlative impression.

To put it briefly, Hume's argument concerning the role of pleasure is based on the mechanism through which an impression of pleasure engenders an idea of pleasure which a belief makes more or less strong. This mechanism leads to emphasizing successively its two constitutive steps - first the impression of pleasure itself; followed by the operation of belief, which governs the transition from the impression to the strength of the resulting idea.

\subsection{The Measurement of Pleasure}

That Hume's conception of pleasure as an impression of sensation is linked to a cardinal measure (that is, giving sense to the comparison of differences between pleasures) has not found universal acceptance. The irreducible heterogeneity of pleasures might be one problem, ${ }^{6}$ like the role played by pleasure in the process leading to action. ${ }^{7}$ One can find

\footnotetext{
${ }^{5}$ Hume keeps on returning to belief as a particular mode of understanding, stronger and more vivid, firstly in Book I of the Treatise (for example, Hume 1739-40, I, p. 96); in the Appendix which completes it and a large part of which is devoted to the point (Hume 1739-40, Appendix, pp. 624-5, 628-9); in the Abstract (Hume 1740, pp. 654, 656); and in the first Enquiry (Hume 1748, pp. 48ff.). Alternatively, he notes exceptional situations in which ideas assume the force of sensations: "in sleep, in a fever, in madness, or in any very violent emotions of the soul" (Hume 1739-40, I, p. 2).

${ }^{6}$ See for instance Pierre Demeulenaere 1996, pp. 36-7.
} 
(more often in the Treatise that in the Enquiries or the Dissertation) certain caveats that prevent us from adopting unreservedly an understanding of pleasure that is Benthamite avant la lettre:

'tis evident, that under the term pleasure, we comprehend sensations, which are very different from each other, and which have only such a distant resemblance as is requisite to make them be expressed by the same abstract term (Hume 1739-40, III, p. 472).

But such caveats serve a purpose different to the valuation of pleasure. That raised here, for example, relates to an explanation of the differences between moral virtues, so that it is not obvious that it is of relevance here, where we are directly interested in the motivation of action. Moreover, it also seems that Hume himself encourages such prudence when, having here drawn attention to the plurality of feelings underlying pleasure, he continues in a tone which, this time, suggests to the modern reader a convergence with Bentham:

A good composition of music and a bottle of good wine equally produce pleasure; and what is more, their goodness is determin'd merely by the pleasure (Ibid.).

This suggests a scalar measure of pleasure as an impression of sensation, by means of a function $\mathrm{p}(\mathrm{x})$ defined over the set of reference of choice $\mathrm{X}$. The properties of this measure can be specified by reference to a passage from Book I of the Treatise in which Hume compares the differences between two pairs of impressions - the noticeable difference between possessing two guineas and three, on the one hand; and the far less noticeable difference in possessing nine hundred and ninety-nine and one thousand, on the other hand (Hume 173940, I, pp. 141-2). If this comparison is interpreted as the claim that differences between pleasures can be entirely preordered ${ }^{8}$, and if to this is added the fact that the zero value of the pleasure function must be invariable relatively to its transformations, since it corresponds to the boundary between pleasure and pain in their narrow sense, then one can conclude that $\mathrm{p}(\mathrm{x})$ is defined up to a positive linear transformation, that is to say, $\mathrm{p}(\mathrm{x})$ is a cardinal measure of pleasure, in which the 0 is non-arbitrary $0 .^{9}$

\footnotetext{
${ }^{7}$ Norman Kemp Smith rejects the idea that Hume was a hedonist, and regards pleasure as one of the efficient causes of action - and not as a final cause. From a different perspective Robert Sugden (2005, pp. 115-7) considers that variations in the passions affecting a desire through the force of the idea of pleasure, even if the impression of pleasure does not change, compromises the rationality of choice (for the opposite point of view see Diaye and Lapidus 2005b).

${ }^{8}$ Hume's comparison might also be interpreted, as rightly suggested by an anonymous referee of this Journal, as a non-transitive indifference. Such an interpretation was already suggested in Lapidus 2000 (pp. 49-51), where Hume's example was interpreted as an attempt to solve what is today called a "problem of choice discrimination".

${ }^{9}$ In other terms, if $p(x)$ is a function of pleasure, then every function $\pi(x)=a p(x)(a>0)$ is also a function of pleasure which represents the same sensations.
} 


\subsection{Beliefs and the Strength of the Idea of Pleasure}

Which leaves beliefs. Hume introduces them as a solution to an enigma. And the starting point of this enigma is, once more, one of the most-cited passages from the Treatise, in which he shows the incapacity of reason to arbitrate between the ends of passions as long as these passions were neither based upon erroneous supposition, nor involved in the choice of means inappropriate to the end in question:

'Tis not contrary to reason to prefer the destruction of the whole world to the scratching of my finger. 'Tis not contrary to reason for me to chuse my total ruin, to prevent the least uneasiness of an Indian, or person wholly unknown to me. (Hume 1739-40, II, p. 416)

If we adhere to the position expressed in this short extract, nothing seems to prevent a Benthamite reading, such that however provocative the expressed preferences might be, they would simply correspond to that which sustained the greatest pleasure (or, more exactly, the smallest pain): the destruction of the world in the first case, or one's own ruin in the second. But the passage immediately following invalidates this possible interpretation - for Hume, and distinct from Bentham, what we prefer does not necessarily coincide with what gives us the most pleasure: ${ }^{10}$

'Tis as little contrary to reason to prefer even my own acknowledg'd lesser good to my greater, and have a more ardent affection for the former than the latter. A trivial good may, from certain circumstances, produce a desire superior to what arises from the greatest and most valuable enjoyment" (Ibid.).

As at other points in the Treatise, there is hardly any doubt that the "good" which Hume has here in mind is that of "pleasure". The reader is confronted by three successive figures, in which what is preferred and chosen can first be considered as conforming to that which provides the most pleasure (the first two examples: the destruction of the world and my own ruin), then as in contradiction to a hypothetical hedonistic choice (in the last example preferring the trivial good). ${ }^{11}$ It is this enigma that Hume seems to want to render commonplace through use of an unsatisfactory metaphor:

[There is not] any thing more extraordinary in this, [preferring a trivial good to my greater good, A.L.] than in mechanics to see one pound weight raise up a hundred by the advantage of its situation. (Ibid.)

The mechanical analogy obviously needs to be made more explicit; where, in this process which leads from the sensation of pleasure to a choice, is the lever to which the "advantage of

\footnotetext{
${ }^{10}$ One can reduce the gap between the two writers by noting that it rests on an essentially nominal difference. It would be possible to assume that, by introducing into the core of the felicific calculus "propinquity" and "certainty" as dimensions of pleasure, Bentham (1789, pp. 38-9) incorporated into what he continued to call "pleasure" elements of belief that, in Hume, permitted the estimation of the force of the idea of pleasure. However, pursuit of this path would deprive us of the possibility of distinguishing, as will later be done, between valuations linked to decision, and those related to welfare.

${ }^{11}$ For one of the rare discussions of the three situations presented in this passage of the Treatise (whereas the literature on Hume's practical reason typically stops after the first two situations), see Cass Weiller 2004.
} 
its situation" refers and which allows pleasure to be both determining and non-representative of desire? Hume responds to this with belief. This touches on the most fundamental aspects of his theory of knowledge. It involves judgement upon facts and includes the entirety of a situation even before any reasoning has occurred (Hume 1739-40, I p. 102). It is created by custom $^{12}$ which establishes general rules ${ }^{13}$ on the basis of past experience through natural relations to which understanding has resort - associations founded upon resemblance, contiguity and causality. ${ }^{14}$ The nature of the natural relations involved is decisive since each of them, in its primary role (causality is constantly present ${ }^{15}$ ) makes it possible to gather under one head domains which economic analysis usually treats separately. Hence, beliefs generated primarily by causality, resemblance and contiguity, relate to problems regarding respectively choice under uncertainty, choice indiscrimination and intertemporal or spatial decision, all of which are dealt with in the course of the Treatise, the Enquiry concerning the Principles of Morals and the Dissertation. ${ }^{16}$

The same impression of pleasure will result in a reduced belief with a more distant object. Hence it will prompt an idea of pleasure reduced in force and vivacity which will now be representative of desire. This loss of force and vivacity can turn out to be decisive, even if the correlative sensation is strong; Hume invokes here "castle-builders"17 who link the idea of intense pleasure to their mental constructions, but lacking the force and vivacity which would raise them to the level of the original sensation, cannot lead to action.

\footnotetext{
12 See especially Hume 1739-40, Appendix pp. 623 ff.

${ }^{13}$ It is the absence of general rules which allows the force and vivacity of ideas to be limited, insofar as these are communicated not through beliefs but, for instance, through poetry or eloquence (Hume 1739-40, Appendix pp. 631-2; see also Hume 1740 p. 654).

${ }^{14}$ On the respective roles of the three natural relations in the formation of beliefs see Francis Dauer (1999), who does however consider that the model of a transfer via natural relations is specific to the Treatise and cannot be found in the Enquiries.

${ }^{15}$ See Harold Noonan (1999, pp. 73-5) for an account of the asymmetry between the relation of causality, to which appeal is always made in the formation of belief, and resemblance or contiguity, which are not treated as necessary to it.

${ }^{16}$ Concerning choice under uncertainty see Hume (1739-40, II, pp. 439 sqq.; 1757, pp. 139 sqq). A remarkable example of indiscrimination (interpreted supra p. 6 as giving rise to some kind of cardinality) is given in Book I (Hume 1739-40, I, pp. 141-2). On intertemporal or interspatial decision see Hume (1739-40, II, pp. 418, 427 sqq.; 1751, pp. 239-40; 1757, pp. 161-2). These different cases are discussed in Lapidus (2000, pp. 42 sqq). One will note that strictly speaking the difficulty of discriminating between pleasures prevents them from being represented by a scalar function of the type $p(x)$, since indiscrimination means that the symmetric part of the underlying binary relation of preference involves intransitivities.

17 This example recurs several times, firstly in Book I of the Treatise (Hume 1739-40, I, p. 97), then in the Appendix (Hume 1739-40, Appendix, pp. 624 and 625). It becomes an "enchanted castle" in the Enquiry on Human Understanding (Hume 1748, p. 50).
} 
This situation can be described and illustrated more formally. Suppose that, just like in standard general equilibrium theory (à la Debreu, for instance), each element $\mathrm{x}$ in the set of reference of choice $\mathrm{X} \subseteq \mathbb{R}^{\mathrm{n}+}$ represents both a bundle of quantities and the date at which this bundle is available. Henceforth, quantities $q$ and date $t$ might be considered respectively as restrictions of $\mathrm{x}$ to its $\mathrm{n}-1$ first components and to its last component. They can therefore be viewed as depending on these elements, i.e. $\mathrm{q}=\mathrm{q}(\mathrm{x}) \in \mathbb{R}^{\mathrm{n}-\mathrm{l}^{+}}$and $\mathrm{t}=\mathrm{t}(\mathrm{x}) \in \mathbb{R}^{+}$. Now, if two elements $\mathrm{x}_{1}, \mathrm{x}_{2} \in \mathrm{X}$ are such that $\mathrm{q}\left(\mathrm{x}_{1}\right)=\mathrm{q}\left(\mathrm{x}_{2}\right)$ whereas $\mathrm{t}\left(\mathrm{x}_{1}\right)<\mathrm{t}\left(\mathrm{x}_{2}\right)$, the pleasure $\mathrm{p}\left(\mathrm{x}_{1}\right)$ and $\mathrm{p}\left(\mathrm{x}_{2}\right)$ that they generate at dates $\mathrm{t}\left(\mathrm{x}_{1}\right)$ and $\mathrm{t}\left(\mathrm{x}_{2}\right)$ is obviously the same, since the quantities involved in each case are the same. On the contrary, the correlative forces of the ideas of pleasure are not determined only by the respective quantities, but also by the date at which they are available. From a Humean point of view, as we shall see, since the pleasure in $t\left(x_{1}\right)$ is closer than the one in $\mathrm{t}\left(\mathrm{x}_{2}\right)$, contiguity gives more force to the idea of pleasure of the former. Denoting these 'forces' $\mathrm{u}\left(\mathrm{x}_{1}\right)$ and $\mathrm{u}\left(\mathrm{x}_{2}\right)$, this means that $\mathrm{u}\left(\mathrm{x}_{1}\right)>\mathrm{u}\left(\mathrm{x}_{2}\right)$. In other words, the respective valuations $\mathrm{u}\left(\mathrm{x}_{1}\right)$ and $\mathrm{u}\left(\mathrm{x}_{2}\right)$ of the forces of the ideas of pleasure indicate that $\mathrm{x}_{1}$ is more desired than $x_{2}$, or $x_{1} R_{2}$. This renders explicit the consequences of a belief, that is, the transformation of a pleasure $\mathrm{p}(\mathrm{x})$ into the force of its idea, $\mathrm{u}(\mathrm{x})$.

In its general form, such a transformation can be viewed as performed by a function $\mathrm{h}($.) of the pleasure $\mathrm{p}$, depending upon $\mathrm{x}$ :

$$
\mathrm{u}(\mathrm{x})=\mathrm{h}(\mathrm{p}(\mathrm{x}), \mathrm{x})
$$

$\mathrm{u}(\mathrm{x})$ is therefore the link between the pleasure $\mathrm{p}(\mathrm{x})$ by which it is generated, and the relation of desire $\mathrm{R}$ which it represents. It also provides the basis for the valuation $\mathrm{D}$ of a decision over a context $\mathrm{S}$, which has the familiar form of the constrained maximisation of utility:

$$
\mathrm{D}=\max _{\mathrm{x} \in \mathrm{S}} \mathrm{h}(\mathrm{p}(\mathrm{x}), \mathrm{x})=\max _{\mathrm{x} \in \mathrm{S}} \mathrm{u}(\mathrm{x})
$$

The form of this relation, along with that of $h($.$) and p($.$) , will be later enriched with the$ progressive introduction of new elements from Humean analysis, namely what will be called the "degree of violence of the passion", denoted $v$, which will require a redefinition of the transformation of pleasure $\mathrm{h}($.) (and consequently of D), and later of the function of pleasure $\mathrm{p}($.) itself. But for the time being, it is possible to specify more closely the form of $h(p(x), x)$, at least in the case where it depends on the action of the relation of contiguity which, coupled to the relation of causality, creates a belief in a future pleasure, transferring therefore into the idea of this pleasure more or less force and vivacity ${ }^{18}$. Quite how this works is described in Book II of the Treatise:

\footnotetext{
${ }^{18}$ It is obvious that, like in equation [1], h depends on $\mathrm{x}$ in two different ways: i) indirectly, as a function of $\mathrm{p}$, it depends on $\mathrm{x}$ through $\mathrm{q}$, but remains independent of $\mathrm{t}$; ii) directly, it depends on $\mathrm{x}$, through its time-dimension $\mathrm{t}$.
} 
The fewer steps we make to arrive at the object, and the smoother the road is, this diminution of vivacity is less sensibly felt, but still may be observed more or less in proportion to the degrees of distance and difficulty.

Here then we are to consider two kinds of objects, the contiguous and remote; of which the former, by means of their relation to ourselves, approach an impression in force and vivacity; the latter by reason of the interruption in our manner of conceiving them, appear in a weaker and more imperfect light. This is their effect on the imagination. If my reasoning be just, they must have a proportionable effect on the will and passions. Contiguous objects must have an influence much superior to the distant and remote. (Hume 1739-40, II: 428)

It is therefore this image of the number of steps that explains that the idea of a pleasure has less force the further removed in time that it is. ${ }^{19}$ Pursuing this metaphor, we might also think that if one covers in imagination the distance that separates us from a future pleasure at a constant speed (the "degree of distance") its rate of depreciation $r$ (or the subjective rate of interest) is itself constant (a "proportionable effect" as Hume writes) so that, assuming continuous time, the force of the idea of a pleasure $\mathrm{x}$ available at $\mathrm{t}(\mathrm{x})$ will be naturally given by the familiar expression:

$$
\mathrm{u}(\mathrm{x})=\mathrm{p}(\mathrm{x}) \mathrm{e}^{-\mathrm{rt}(\mathrm{x})}
$$

Even if such clarification falls short of Hume's contribution to the intertemporal aspects of decision-making, ${ }^{20}$ it nonetheless facilitates understanding of the specificity of a theory articulating impression, belief and idea in the explanation of action. Belief, which can be given a numerical expression as a discounting factor (in this case $\mathrm{e}^{-\mathrm{rt}}$ ), lies between the impressions (here $\mathrm{p}(\mathrm{x})$ ) from which it acquires, according to the Treatise, force and vivacity (Hume 1739-40, I, p. 98), and ideas that are mere conceptions for which force and vivacity are robbed of meaning. Hence my belief may be more or less strong, like an impression, but that does not mean that it is an impression, since it can be true or false in the same way as an idea, and not satisfied like, for instance, a desire. But symmetrically, although this approaches an idea, it is no more an idea, since the belief that it will turn out nice tomorrow can be either strong or weak, or even true or false: this changes nothing in the simple idea of a sunny day. ${ }^{21}$ Hume went to great lengths to convince his reader that a world in which either impressions or ideas could of themselves lead to action was not viable (see Book I, Part III Ch. 10 of the

\footnotetext{
${ }^{19}$ This is made explicit in Book III of the Treatise, and applied to the analysis of the origin of justice. It makes possible an understanding that preference for the present is a consequence (and not always a very happy one, according to Hume) of the natural functioning of imagination, which always lends more force to the idea - even if the sensation is identical - of a present pleasure (Hume 1739-40, III, p. 535). One encounters the same thesis in the Enquiry concerning the Principles of Morals (Hume 1751, p. 205) and in the Essays (Hume 1777, Of the Origin of Government [1774], p. 38).

${ }^{20}$ Hume's treatment of intertemporal decision has not attracted much in the way of commentary. See however Lapidus (2000, pp. 45-9); Gordon (2003); Palacios-Huerta (2003).

${ }^{21}$ Belief is also not for Hume a new idea which would be attached to a previous conception (see for instance Hume 1740, p. 654).
} 
Treatise, Hume 1739-40 I pp. 118 ff.). From this there follows a disconnection between an impression of pleasure determining passions but not measuring them, and a desire which prompts decision, though its associated measure, the force of the idea of pleasure, does not correspond to the underlying impression of pleasure. It is in this tension between the force of the idea of pleasure and the impression of pleasure that the distinction between two evaluative levels is placed, the one of decision, the other of welfare.

\section{The Valuations of Well-Being and the Violence of the Passions}

\subsection{Interest Confronted with desire}

The possibility of a divergence between what is optimal from the decisional perspective and what is optimal from an evaluative perspective upon welfare occurs in the course of a discussion in Book II of the Treatise whose terms are repeated in the Dissertation, opposing interest to the motive for and result of action:

Men often act knowingly against their interest: For which reason, the view of the greatest possible good does not always influence them. Men often counter-act a violent passion in prosecution of their interests and designs: 'Tis not, therefore, the present uneasiness alone which determines them. In general we may observe that both these principles [the calm passion and the violent passion] operate on the will; and where they are contrary, that either of them prevails, according to the general character or present disposition of the person. What we call strength of mind, implies the prevalence of the calm passions above the violent (Hume 1739-40, I, p. 418; see also Hume 1757, p. 162).

This passage calls for some considerable effort of clarification, directed first of all to the question of "interest", followed by the issue of the "violence" of the passions.

The "interest" which Hume examines to determine whether it is satisfied or not is assimilated to the "greater good", which as we have already seen is intended as the greatest sensation of pleasure (Hume 1739-40, II p. 439). Relative to a context of choice S belonging to the domain of choice F, interest is then the greatest pleasure that could be given by one of the elements of $\mathrm{S}$ :

$$
\mathrm{I}=\max _{\mathrm{x} \in \mathrm{S}} \mathrm{p}(\mathrm{x})
$$

It is when faced with this interest that Hume imagines a choice that will either conform to it or be inferior in terms of pleasure, and which will be the greatest element of S not in the sense of $\mathrm{p}(\mathrm{x})$ but, as in [2], in the sense of $\mathrm{u}(\mathrm{x})=\mathrm{h}(\mathrm{p}(\mathrm{x}), \mathrm{x})$.

Reference to the "violence" of the passions makes this apparatus more complex. As soon as Hume turns to this, he understands it as an emotional intensity. As distinct from "calm passion" - which shares low emotional intensity with the exercise of reason so that it is sometimes confused with it (Hume 1739-40, II, p. 417) - "violent passion", which is commonly regarded as "passion" in the proper sense, is according to Hume "a violent and sensible emotion of the mind" (ibid. p. 437). The degree of violence thus expresses the excitement of "the spirits" (ibid. p. 420), their "emotion" (ibid. p. 421) or their arousal (ibid. 
p. 422). However, the characteristic of the emotional intensity constituting the violence of a passion is that it controls the action of the relation of contiguity. The examples which Hume gives regarding the way of "govern[ing] a man and push him to any action" (ibid. p. 419) suggest that the belief in a near pleasure is greater if the desire which constitutes its object is violent. From this we can say that the preference for the present expressed by $r$ varies positively with the degree of violence $\mathrm{v}$ of the underlying passion and is zero when $\mathrm{v}$ takes the value $\hat{v}$ corresponding to the degree of violence of a calm passion. Taking into account this element necessarily makes explicit the role of $\mathrm{v}$ in the expression of the force of the idea of pleasure. This leads to rewriting [1] and [3] as follows ${ }^{22}$ :

$$
\mathrm{u}(\mathrm{x}, \mathrm{v})=\mathrm{h}(\mathrm{p}(\mathrm{x}), \mathrm{x}, \mathrm{v})=\mathrm{p}(\mathrm{x}) \mathrm{e}^{-\mathrm{r}(\mathrm{v}) \mathrm{t}(\mathrm{x})}
$$

with the condition that $v \geq \hat{v} ; r_{v}>0 ; r(\hat{v})=0$

This states that the same object $\mathrm{x}$ placed at a future date $\mathrm{t}(\mathrm{x})$ is discounted more strongly, the greater is the degree of violence of the associated passion. Equation [2], which expresses the decision taken in a choice context $\mathrm{S}$, has then also to be rewritten as a function of the degree of violence:

$$
\mathrm{D}=\max _{\mathrm{x} \in \mathrm{S}} \mathrm{h}(\mathrm{p}(\mathrm{x}), \mathrm{x}, \mathrm{v})=\max _{\mathrm{x} \in \mathrm{S}} \mathrm{u}(\mathrm{x}, \mathrm{v})
$$

Now, we can return to Hume's argument (1739-40, II, p. 418) where he presents two situations that differ only in respect of the degree of violence to which an individual is submitted. In these two situations, called hereafter A and B, we consider only violent and calm passions respectively. They do however share the same context of choice $S=\left\{x_{1}, x_{2}\right\}$, for which $\mathrm{t}_{1}=\mathrm{t}\left(\mathrm{x}_{1}\right)<\mathrm{t}_{2}=\mathrm{t}\left(\mathrm{x}_{2}\right)$, where the interest $\mathrm{I}_{\mathrm{A}}=\mathrm{I}_{\mathrm{B}}$ of the individual concerned leads each time to the privileging of the distant object $x_{2}$. The degrees of violence in each situation are given by $v_{A}$ and $v_{B}$ (with $v_{A}>v_{B}$ and $v_{B}=\hat{v}$, corresponding to the degree of violence of calm passion, so that $\left.r\left(v_{A}\right)>r\left(v_{B}\right)=0\right)$. The corresponding forces of the ideas of pleasure are expressed by the transformation functions $\mathrm{h}\left(\mathrm{p}(\mathrm{x}), \mathrm{x}, \mathrm{v}_{\mathrm{A}}\right)$ and $\mathrm{h}\left(\mathrm{p}(\mathrm{x}), \mathrm{x}, \mathrm{v}_{\mathrm{B}}\right)$, and they lead respectively to choose $\mathrm{x}_{1}$ and $\mathrm{x}_{2}$. These two situations can be presented as follows:

- Situation $A$ - the object that conforms to interest $\left(x_{2}\right)$ is not the one that conforms to the decision $\left(x_{1}\right)$ :

$$
\left\{\begin{array}{l}
\mathrm{I}_{\mathrm{A}}=\max _{\mathrm{x} \in \mathrm{S}} \mathrm{p}(\mathrm{x})=\mathrm{p}\left(\mathrm{x}_{2}\right) \\
\mathrm{D}_{\mathrm{A}}=\max _{\mathrm{x} \in \mathrm{S}} \mathrm{h}\left(\mathrm{p}(\mathrm{x}), \mathrm{x}, \mathrm{v}_{\mathrm{A}}\right)=\mathrm{u}\left(\mathrm{x}_{1}, \mathrm{v}_{\mathrm{A}}\right)=\mathrm{p}\left(\mathrm{x}_{1}\right) \mathrm{e}^{-\mathrm{r}\left(\mathrm{v}_{\mathrm{A}}\right) \mathrm{t}_{1}}
\end{array}\right.
$$

\footnotetext{
${ }^{22}$ For the sake of simplicity, the original notation $u($.$) and h($.$) from equations [1], [2], and [3] are kept up all$ along this paper, although strictly speaking, the corresponding functions are not defined on the same sets.
} 
- Situation B - the object that conforms to interest $\left(x_{2}\right)$ is also that which conforms to the decision $\left(x_{2}\right)$ :

$$
\left\{\begin{array}{l}
\mathrm{I}_{\mathrm{B}}=\max _{\mathrm{x} \in \mathrm{S}} \mathrm{p}(\mathrm{x})=\mathrm{p}\left(\mathrm{x}_{2}\right) \\
\mathrm{D}_{\mathrm{B}}=\max _{\mathrm{x} \in \mathrm{S}} \mathrm{h}\left(\mathrm{p}(\mathrm{x}), \mathrm{x}, \mathrm{v}_{\mathrm{B}}\right)=\mathrm{u}\left(\mathrm{x}_{2}, \mathrm{v}_{\mathrm{B}}\right)=\mathrm{p}\left(\mathrm{x}_{2}\right) \mathrm{e}^{-\mathrm{r}\left(\mathrm{v}_{\mathrm{B}}\right) \mathrm{t}_{2}}=\mathrm{p}\left(\mathrm{x}_{2}\right)
\end{array}\right.
$$

The calculation of interest $\left(\mathrm{I}_{A}\right.$ et $\left.\mathrm{I}_{B}\right)$ opens a path to an appreciation of choice independent of decisional calculation $\left(\mathrm{D}_{\mathrm{A}}\right.$ et $\left.\mathrm{D}_{\mathrm{B}}\right)$. Its effect is to cancel out the repercussions, arising from movements in the imagination and the impassioned state, for the force of the idea of pleasures both near and far which govern the calculus of decision. In this way, the two pleasures' respective contributions to interest will not depend upon the dates at which they arise. Nonetheless, by privileging potential structures of choice which abstract from those forces linked to the ideas of pleasure, it remains a valuation deprived of any decisional authority. Hence the calm passion, in which the valuation of decision and that of interest coincide $\left(D_{B}=\right.$ $I_{B}$ ), assumes a remarkable importance, for not only will we make decisions in conformity with the relative force of the ideas of pleasure of the different objects presented to us, but, moreover, it is thanks to this that our choice provides us with the greatest pleasure. It is therefore possible to characterise a state of calm passion as a state of degree of violence $v=\hat{v}$ where the decisional calculus leads to a choice $\hat{x}$, maximising pleasure on the one hand, and resulting from a simple calculus of interest, on the other hand:

$$
\left.\begin{array}{l}
D=\max _{x \in S} h(p(x), x, v) \\
I=\max _{x \in S} p(x) \\
D=I
\end{array}\right\} \rightarrow \hat{x}, \hat{v}
$$

\subsection{Is Happiness Distinct from Interest?}

While Hume in his Enquiry concerning the Principles of Morals comes back to the comparative effects of a calm and of a violent passion so as to attribute, as he had already done in Book II of the Treatise, the prevalence of the one or the other on the "strength of mind", ${ }^{23}$ one could consider the reference to "happiness" as no more than an inconsequential terminological variation on the theme of interest:

All men, it is allowed, are equally desirous of happiness; but few are successful in the pursuit: One considerable cause is the want of strength of mind, which might enable them to resist the temptation of present ease or pleasure, and carry them forward in the search of more distant profit and enjoyment. Our affections $[\ldots]$ form certain rules of conduct, and certain measures of preference of one above another: and these decisions, though really the result of our calm passions and propensities, (for what else can

\footnotetext{
${ }^{23}$ Book II of the Treatise also speaks of "strength of mind" as well as general character", or the "present disposition" of the person concerned (Hume 1739-40, II, p. 418; see also Hume 1757, p. 162).
} 
pronounce any object eligible or the contrary?) are yet said, by a natural abuse of terms, to be the determinations of pure reason and reflection. (Hume 1751, p. 239)

The following lines seem to confirm the closeness of this text to the perspective adopted in the Treatise since Hume there once more distinguishes as above two situations of types A and $\mathrm{B}$, emphasising however more vigorously the harmful effects of the choice achieved in situation A when, governed by a violent passion, the individual concerned had preferred the close object $\left(\mathrm{x}_{1}\right)$ to the distant object $\left(\mathrm{x}_{2}\right)$. And he concludes as follows:

And however poets may employ their wit and eloquence, in celebrating present pleasure, and rejecting all distant views to fame, health, or fortune; it is obvious, that this practice is the source of all dissoluteness and disorder, repentance and misery. A man of a strong and determined temper adheres tenaciously to his general resolutions, and is neither seduced by the allurements of pleasure, nor terrified by the menaces of pain; but keeps still in view those distant pursuits, by which he, at once, ensures his happiness and his honour. (Ibid., pp. 239-40)

The essential difference between the extract from Book II of the Treatise and that from the second Enquiry appears to consist in the distinct content of the elegy to calm passion. It is no longer only interest as it arises in the Treatise, nor the psychological characteristics of the individual, that enables calm passion to prevail, but the dignity of the distant object, the social order, honour, happiness and unhappiness. One detects here that which John Immerwahr (1992) has revealed by working conjointly on the Treatise and the Essays: in Hume there are numerous strong reasons for favouring calm passions; reasons that touch upon religion, morality, politics and happiness.

And so we come back to happiness. Like interest, happiness is linked to calm passion. There are however some distinctive elements suggesting that, for Hume, happiness, unlike interest, does not only indicate the greatest impression of pleasure, but invites examination of the manner in which passions do themselves determine it. That is the case in those passages from the second Enquiry that are cited below, when he evokes this aptitude of the calm passions associated with happiness to let us know if an object is "eligible" (Hume 1751, p. 239). The reference to eligibility could simply express conformity to interest; but the term seems to carry another meaning. All the same, while he continues by affirming that the pursuit of close pleasures, governed by a violent passion is the "source of all dissoluteness and disorder, repentance and misery" (ibid.), he says more than the simple fact that there is a choice for which the impression of pleasure will not be as high as possible, because it will not conform to interest: even without further qualification, one understands that "misery" does not only confine us to the lower levels of the scale of pleasures, but also blocks our access to higher degrees. Or again, while he eulogises the man of "strong and determined temper" for whom calm passion prevails, by writing that he "is neither seduced by the allurement of pleasure (ibid.) he suggests a complex operation, for it is exactly pleasure that guides us: either, from a decisional point of view, through the force of the idea of pleasure; or, from an evaluative point of view, through the impression of pleasure. 
The key to interpretation of the preceding passages from 1751 concerns the understanding of happiness that Hume puts forward, an understanding from which it emerges that it cannot be reduced to identification with interest. In this respect the Essays are more explicit than his better known philosophical works. ${ }^{24}$ The essay on "Refinement in the Arts" 25 clearly expresses the principle that governs the realisation of happiness by distinguishing its constituting elements:

Human happiness [...] seems to consist in three ingredients; action, pleasure, and indolence: And though these ingredients ought to be mixed in different proportions, according to the particular disposition of the person; yet no one ingredient can be entirely wanting, without destroying, in some measure, the relish of the whole composition. (Hume 1777, Of Refinement in the Arts [1752], pp. 26970)

We need to examine more closely the substance of the two "ingredients" that, along with pleasure, make up happiness. But the very way that Hume sets this up does mean that pleasure is by itself insufficient to characterise happiness. In the following discussion there is suggestion of the consequences of a lack of proportion between indolence and action. If indolence predominates, it prompts "a languor and lethargy, that destroys all enjoyment" (Ibid., p. 240). By contrast, if action dominates, the "quick march of the spirits, which takes a man from himself, and chiefly gives satisfaction, does in the end exhaust the mind" (Ibid.). From this it follows that if happiness is increased with pleasure, it reaches a maximum where action and indolence are in a specific proportion, and diminishes if this proportion is altered That reference to action and indolence indicates another modality of the degree of violence of the passions is revealed in Hume's essay on "The Sceptic": 26

To be happy, the passion must neither be too violent nor too remiss. In the first case, the mind is in a perpetual hurry and tumult; in the second, it sinks into a disagreeable indolence and lethargy. (Hume 1777, The Sceptic [1742], p. 167)

Indolence and action appear to be two behavioural characteristics that relate to two mental states, respectively "lethargy" and "tumult", and accompany two states of the passions, the one inactive and the other violent. The same impression of pleasure contributes the most to

\footnotetext{
${ }^{24}$ After 1741, once Hume had taken account of the poor reception given to the Treatise, he published, and then revised and augmented a collection of essays, republished up to the posthumous edition of 1777 under the title Essays Moral, Political and Literary.

${ }^{25}$ In the 1752 edition of the Essays where it appeared for the first time this essay was entitled "Of Luxury".

${ }^{26}$ Published from 1742, this essay is one of a set of four texts ("The Epicurean", "The Stoic", "The Platonist", "The Sceptic") in which Hume presents "sects, that naturally form themselves in the world, and entertain different ideas of human life and of happiness" (Hume 1777, The Epicurean [1742], p. 138 n. 1). There is disagreement whether this essay corresponds to Hume's position. Here we follow the interpretation of Immerwahr (1989) who argues that, while none of the four essays coincides with the theses advanced in the Treatise, "The Sceptic" comes closest to them. The differences noted by Immerwahr principally concern the possibility of controlling the passionate state which can lead to happiness, in particular the violence of the passions.
} 
happiness when the individual occupies this intermediary position between the lethargy and tumult that accompanies the appropriate proportion of action and indolence, so long as the passionate state is neither remiss nor violent, which is to say that he is governed by calm passion.

Our understanding of the influence of the degree of violence is therefore modified. While the Treatise presents calm passion as the lower boundary of the violence of the passions, the Essays allow this boundary to be crossed: a remiss passion is still less violent than calm passion. The indolence associated with it does not seem to suggest that from a decisional point of view, the present would be discounted in favour of the future: under the influence of a remiss passion, the present is worth as much as the future, or rather, worth as little. This idea, that the present be worth as little as the future, deserves a more precise investigation. If the fall in degree of violence of the passions below that of calm passion does not affect the preference for the present, that is the relative force of the ideas of pleasure, then one is prompted to look for an other influence than the one already acknowledged in the transformation function $\mathrm{h}(\mathrm{p}(\mathrm{x}), \mathrm{x}, \mathrm{v})$.

\subsection{Happiness When Interest no Longer Suffices}

Additional influence of the degree of violence of the passions, beyond what could exclusively concern discounting of the future, enlarges the distance between happiness and interest. A reading of the Essays does indeed supplement our analysis on two points relating to the determination of the greatest happiness. They are the effects of the degree of violence respectively on the impression of pleasure itself, and on the passionate dynamics.

As explained in the essay "On Refinement in the Arts" (Hume 1777, p. 240), that which through variation in the degree of violence of passions, "does in the end exhaust the mind" action - or produces "a languor and lethargy, that destroys all enjoyment" - indolence - does not lead solely to a transformation of our desires that leads us, for example, to prefer this close object to that distant object: it also influences our capacity to feel pleasure. It does not only concern pleasure as an idea, modulating a belief, but it also works on the origin of the mechanism, acting on the impression of pleasure itself, all the stronger as the passion is calmer. As Hume writes in "The Sceptic" (Hume 1777 p. 166; see also p. 172), "that it is not from the value or worth of the object, which any person pursues, that we can determine his enjoyment, but merely from the passion with which he pursues it [...]. Objects have absolutely no worth or value in themselves. They derive their worth merely from the passion". This leads us to reformulate the relations [7]-[8] from which we obtained the valuations associated respectively with interest and with decision in order to take into account the 
modification into the pleasure function, which henceforth has the form $\mathrm{p}(\mathrm{x}, \mathrm{v})^{27}$. The partial derivative $p_{v}$ of $p$ in relation to $v$ is at first positive, then negative. The degree of violence $\hat{\mathrm{v}}$ for which $\mathrm{p}_{\mathrm{v}}$ is zero can be understood as an expression of the calm passion, which is separating remiss passions $(\mathrm{v}<\hat{\mathrm{v}})$ from violent passions $(\mathrm{v}>\hat{\mathrm{v}})$, and ensures that for a given $\mathrm{x}, \mathrm{p}(\mathrm{x}, \mathrm{v})$ is a maximum. When transferred into the terms of the preceding passage from the second Enquiry, and with the clarifications that the Essays permit, situations A et B above (equations [7] and [8]), where $v_{B}=\hat{v}$ corresponds as before to the degree of violence of calm passion, can be rewritten as follows:

- $\quad$ Situation A :

$$
\left\{\begin{array}{l}
\mathrm{I}_{\mathrm{A}}=\max _{\mathrm{x} \in \mathrm{S}} \mathrm{p}\left(\mathrm{x}, \mathrm{v}_{\mathrm{A}}\right)=\mathrm{p}\left(\mathrm{x}_{2}, \mathrm{v}_{\mathrm{A}}\right) \\
\mathrm{D}_{\mathrm{A}}=\max _{\mathrm{x} \in \mathrm{S}} \mathrm{h}\left(\mathrm{p}\left(\mathrm{x}, \mathrm{v}_{\mathrm{A}}\right), \mathrm{x}, \mathrm{v}_{\mathrm{A}}\right)=\mathrm{u}\left(\mathrm{x}_{1}, \mathrm{v}_{\mathrm{A}}\right)=\mathrm{p}\left(\mathrm{x}_{1}, \mathrm{v}_{\mathrm{A}}\right) \mathrm{e}^{-\mathrm{r}\left(\mathrm{v}_{\mathrm{A}}\right) \mathrm{t}_{1}}
\end{array}\right.
$$

- $\quad$ Situation B :

$$
\left\{\begin{array}{l}
\mathrm{I}_{\mathrm{B}}=\max _{\mathrm{x} \in \mathrm{S}} \mathrm{p}\left(\mathrm{x}, \mathrm{v}_{\mathrm{B}}\right)=\mathrm{p}\left(\mathrm{x}_{2}, \mathrm{v}_{\mathrm{B}}\right) \\
\mathrm{D}_{\mathrm{B}}=\max _{\mathrm{x} \in \mathrm{S}} \mathrm{h}\left(\mathrm{p}\left(\mathrm{x}, \mathrm{v}_{\mathrm{B}}\right), \mathrm{x}, \mathrm{v}_{\mathrm{B}}\right)=\mathrm{u}\left(\mathrm{x}_{2}, \mathrm{v}_{\mathrm{B}}\right)=\mathrm{p}\left(\mathrm{x}_{2}, \mathrm{v}_{\mathrm{B}}\right) \mathrm{e}^{-\mathrm{r}\left(\mathrm{v}_{\mathrm{B}}\right) \mathrm{t}_{2}}=\mathrm{p}\left(\mathrm{x}_{2}, \mathrm{v}_{\mathrm{B}}\right)
\end{array}\right.
$$

This representation shows up an element that has not been considered in the discussion of the relevant passages from the Treatise: if account is taken of the incidence of the degree of violence of the passions on the sensation of pleasure, even if the valuations of decision and of interest in $B$ remain the same $\left(D_{B}=I_{B}\right)$ and the option conforming to the interest of the agent is also the same between $\mathrm{A}$ and $\mathrm{B}$ (the distant object $\mathrm{x}_{2}$, which could have been not the case), this interest will however be less in $A$ than in $B$ : since $v_{B}=\hat{v}<v_{A}$ corresponds to the calm passion for which $\mathrm{p}\left(\mathrm{x}_{2}, \mathrm{v}\right)$ is at a maximum relatively to $\mathrm{v}$, it can be inferred from this that the greatest happiness noted by Hume is $\mathrm{J}=\max \left(\mathrm{I}_{\mathrm{A}}, \mathrm{I}_{\mathrm{B}}\right)=\mathrm{I}_{\mathrm{B}}$ that is, the interest manifested in the context of calm passion.

But going further than this exemplar:

- it is possible to imagine that the context of choice is such that even more violent passions lead to a choice identical to that of calm passion $\left(D_{A}\right.$ and $D_{B}$ lead to the choice of $\left.x_{2}\right)$;

- and, especially, one cannot any more avoid the possibility that, given an identical context of choice, different objects are in conformity with interest when the degrees of violence of the situations of choice differ (for example, if $\mathrm{I}_{\mathrm{A}}=\mathrm{p}\left(\mathrm{x}_{1}, \mathrm{v}_{\mathrm{A}}\right)$ and $\mathrm{I}_{\mathrm{B}}=\mathrm{p}\left(\mathrm{x}_{2}, \mathrm{v}_{\mathrm{B}}\right)$ ).

It is thus obvious that equation [4] regarding the calculus of interest has also to be rewritten to take account of the influence of the violence of the passions upon the impression of pleasure:

\footnotetext{
${ }^{27}$ For the sake of simplicity again, like supra, p. 7, the original notation $\mathrm{p}($.$) is kept up all along this paper,$ although strictly speaking, it is now defined on $(x, v)$ instead of $x$.
} 


$$
\mathrm{I}(\mathrm{S}, \mathrm{v})=\max _{\mathrm{x} \in \mathrm{S}} \mathrm{p}(\mathrm{x}, \mathrm{v})
$$

The reference to happiness is thus the occasion to establish an explicit comparison between the levels of interest attained in situations which might differ from each other by the violence of passion, and possibly by the chosen objects. The greatest happiness will therefore correspond to a maximum of interest, even when the violence of the passions can vary:

$$
\mathrm{J}=\max _{\mathrm{v}} \mathrm{I}(\mathrm{S}, \mathrm{v})=\max _{\mathrm{v}} \max _{\mathrm{x} \in \mathrm{S}} \mathrm{p}(\mathrm{x}, \mathrm{v})
$$

So calm passion is not only desirable because it prompts us to choose that which answers to our interest, but also because it leads us to choices which could have moved away from our interest with more remiss or more violent passions, and which represent, relatively to both the context of choice and the degree of violence, the highest reachable level of interest.

\subsection{The Effect of the Passionate Dynamic}

The degree of violence in the passions leads to yet another influence upon happiness. Whether violent or calm, a passion is not just a state, but an element in a passionate dynamic that lends it direction, tracking subsequent affective investments related to other objects ordered by other desires. From this perspective, the characteristic of calm passion is, for Hume, not limited to being the emotional state that will here and there ensure the most pleasure: it leads to other passions through the double relation of ideas and impressions, which will themselves bear more pleasures, and which are in a way more durable than that which could be realised by a more violent passion. Hume gives many examples of this, showing for instances that violent passions relate to more ephemeral objects, capable of quicker, or less easily attainable, satiation: "where the temper is the best disposed for any enjoyment", he writes, "the object is often wanting" (Hume 1777, The Sceptic [1742] p. 167). There are of course many reasons why the paths taken by the passions might be divergent. But one explanation seems to predominate: this concerns the fact that for the individual involved, violent passions are directed to external objects, and calm passions to internal ones. It is again in "The Sceptic" that Hume explains:

"[T]he passions, which pursue external objects, contribute not so much to happiness, as those which rest in ourselves; since we are neither so certain of attaining such objects, nor so secure in possessing them. A passion for learning is preferable, with regard to happiness, to one for riches. (Hume 1777, pp. 167-8)

This line of separation between calm and violent passions which, although all passions could in principle be involved, ${ }^{28}$ distinguishes them in terms of the preferential nature, internal or external, of their object, is laid out in especial detail in what was the introductory text to the

\footnotetext{
${ }^{28}$ Following Árdall (1966, pp. 10-1), we will consider that all passions, direct or indirect, are capable of being calm or violent. The issue is not however entirely clear, and raises a more general discussion on the classification of the passions (see Fieser 1992).
} 
first edition of the Essays in 1741, "Of the Delicacy of Taste and Passion" (Hume, 1777, pp. 3ff.). After the initial failure of the Treatise this essay presents an opportunity for terminological renewal, "taste" and "passion" replacing "calm passion" and "violent passion" respectively, "delicacy" indicating the passionate form that prevails. When he here details the reasons for which a calm passion, through a "cultivated taste for the polite arts", "improve[s] [...] our sensibility for all the tender and agreeable passions" (Ibid., p. 6) and escape the desires and objects that characterise a violent passion, Hume notes these changes that determine the evolution of our own sensibility:

"[N]othing is so improving to the temper as the study of the beauties, either of poetry, eloquence, music, or painting. [...] The emotions which they excite are soft and tender. They draw off the mind from the hurry of business and interest; cherish reflection; dispose to tranquillity. (Hume 1777, Of the Delicacy of Taste and Passion [1741], pp. 6-7)

If the different elements drawn from the "Delicacy of Taste" and from the "Sceptic" are combined, the position that Hume adopts can be seen to be articulated upon the three following propositions:

1. The degree of violence of the passions tends to become increasingly rigid in the course of a passionate trajectory.

2. Pleasure relating to a choice made at the end of a passionate trajectory is all the more high since it results from a calm trajectory.

3. The modifications of desires, of the sets of reference and of the contexts of choice, are not completely anticipated along a passionate trajectory.

Clearly these propositions do not all have the same status and their scope merits discussion.

First propositions 1 and 2. These appear in Hume's writings as conjectures, ${ }^{29}$ but sufficiently solid to support the thesis that a calm passion will lead to the greatest happiness. More formally, in terms of the decision algorithm developed in Diaye and Lapidus (2005a, pp. 1035), a mechanism for the revision of preferences, of the choice set and the domain of choice, will lead to a stable situation characterised by general preferences $\mathrm{R}(\mathrm{v})$ and contextual preferences $R_{S}(v)$, a set of reference of choice $X(v)$, a domain of choice $F(v)$ and a stabilised final degree of violence of the passions $\mathrm{v}^{*}(\mathrm{v})$, all dependent upon the initial degree of violence v. From this there also results the final context of choice $S^{*}(v)$, in which will be effected the final decision of the agent. His greatest happiness will then correspond to the potential choice and to the degree of violence of the initial passion which would ensure to him the greatest pleasure, in a context of choice depending on the initial degree of violence. Again, this leads to a rewriting as follows of equation [13] which gives the greatest happiness:

\footnotetext{
${ }^{29}$ In the Treatise, the second Enquiry and the Dissertation (for example, Hume 1739-40, II, pp. 418-9; 1751, pp. 239-40; 1757, pp. 161-2), Hume gives many examples of modifications both endogenous and exogenous in the violence of passions, leading to qualification of Proposition 1. See also Diaye and Lapidus 2007.
} 


$$
\mathrm{J}=\max _{\mathrm{v}} \mathrm{I}(\mathrm{S} *(\mathrm{v}), \mathrm{v} *(\mathrm{v}))=\max _{\mathrm{v}} \max _{\mathrm{x} \in \mathrm{S}^{*}(\mathrm{v})} \mathrm{p}(\mathrm{x}, \mathrm{v} *(\mathrm{v}))
$$

Propositions 1 and 2 above lead to the admission that calm passion is that which corresponds to the degree of violence for which the trajectory followed by the passion remains calm from the outset $(\mathrm{v}=\hat{\mathrm{v}})$ to the completion of the process $\left(\mathrm{v}^{*}(\hat{\mathrm{v}})=\hat{\mathrm{v}}\right)$. In such a case, the choice $\hat{x}$ which is achieved ensures that the valuation of the decision (D) is not only equal to the valuation of the interest (I) like in [9]:

$$
\left.\begin{array}{l}
\mathrm{D}=\max _{\mathrm{x} \in \mathrm{S}^{*}(\mathrm{v})} \mathrm{h}\left(\mathrm{p}\left(\mathrm{x}, \mathrm{v}^{*}(\mathrm{v})\right), \mathrm{x}, \mathrm{v}^{*}(\mathrm{v})\right) \\
\mathrm{I}=\max _{\mathrm{x} \in \mathrm{S}^{*}(\mathrm{v})} \mathrm{p}\left(\mathrm{x}, \mathrm{v}^{*}(\mathrm{v})\right) \\
\mathrm{D}=\mathrm{I}
\end{array}\right\} \rightarrow \hat{\mathrm{v}}, \hat{\mathrm{x}}
$$

but also, as Hume conjectured it, to the greatest happiness ( $\mathrm{J}$ ) as given by [14]. Hume therefore proposes that calm passions will tend to lead us towards our greatest happiness not only by diminishing the discount of the future, which makes us follow our interest in a given context of choice, but by also creating other contexts of choice and by transforming our preferences, such that the pleasure that we would derive from our decision be more important than that given to us by any other choice, whether in this context of choice or in another context generated by a more remiss or more violent initial passion - that is, by any other $\mathrm{v} \neq \hat{\mathrm{v}}$. Following our interest would thus engender some kind of virtuous trajectory, along which we would be led towards our greater happiness.

Proposition 3 above should not surprise the reader familiar with the Humean theory of passions, from which it follows. It does however make it possible to clarify an important debate concerning the place of the essay on "The Sceptic" in Hume's philosophical work. Indeed, in this text, the speaker to whom Hume lends his voice can only recognize the vanity in his conception of happiness, for achieving it would suppose an emotional control which will be always denied to him. At first sight, as Robert Fogelin notes (1985, pp. 117ff.), Hume's own position is hardly any different to that of his character. An example is given by Hume's hostility to the doctrine of free-will when he considers the will as a part of the passions $^{30}$. By contrast, John Immerwahr (1989) notes the distance that Hume sometimes adopts with respect to the speaker in "The Sceptic" so as to promote an emotional control that would enable us to decide to bring ourselves closer to happiness; and if this does justice to the leading role of calm passions, it also seems to introduce into the theory of passions an authority over affectivity hitherto lacking.

\footnotetext{
${ }^{30}$ See the third part of Book II of the Treatise, especially the sections dealing with liberty and necessity (Hume 1739-40, II, pp. 399ff.); and for a discussion, Diaye and Lapidus (2005a pp. 98-9).
} 
The textual arguments that could sustain Immerwahr's interpretation essentially rely upon a long footnote in which Hume puts forwards some reservations on the Sceptic's position concerning the alleged incapacity of philosophical reflection of altering the course of our passions: "The Sceptic, perhaps, carries the matter too far", as Hume writes (Hume 1777, The Sceptic [1742], p. 177 n.). These reservations assume the form of a number of propositions that could prompt the speaker to a greater confidence in our capacities of achieving happiness. None of them appear to undermine the emphasis placed on necessity in the Treatise, in the explanation of the functioning of the will. Except this imaginary piece of dialogue:

Propose not a happiness too complicated. But does that depend on me? Yes: The first choice does. Life is like a game: One may choose the game: And passion, by degrees, seizes the proper object. (Hume 1777, The Sceptic [1742], p. 178 n.)

Taken literally, this means that once the degree of violence of the passions is fixed, the passionate trajectory escapes our control ("passion, by degrees, seizes the proper object") while the initial choice, in a rather surprising fashion, yet in conformity with Immerwahr's interpretation, will depend upon us ("One may choose the game").

It is here that proposition 3 above, concerning our ignorance of the modifications that might arise in the course of a passionate trajectory, is quite decisive in showing that such a control upon our lives is not a consequence of a new freedom which would enable us to escape from the rules of the passions. We must take seriously the metaphors of "game" and "object" that Hume introduces. The game, here, testifies that we are ignorant of its outcome. This latter could usually not be fully anticipated. Calm or violent, we do not know where our passionate trajectory will lead us. In other words, neither $\mathrm{S}^{*}(\mathrm{v})$, nor $\mathrm{R}(\mathrm{v})$ are known to us.

Nonetheless, as in many other mental activities that Hume also describes (mathematics, the search for truth, or as here, gambling), our emotions can be invested as desire and as aversion. A calm passion and a violent passion can then lead to the privileging of, respectively, a remote object and a close object: we do not yet know them and perhaps will always ignore at least one of them. However, we know that there are two possible games - that of calm passion, and that of violent passion. We also know how to begin one of the possible games, that is, by choosing it - choosing to follow our interest or not, wherever it may lead. As long as they are not initiated these games are neither close nor remote: they are simply within our scope. We believe more or less in the idea of pleasure that they will convey, even in ignorance of the precise nature of their outcome. It is from this belief and from the idea of this pleasure that our decision to choose one or the other arises. According as we choose to follow our interest or not, our passionate trajectory will be calm or violent and the "objects" to which it leads will depend upon its degree of violence. But, our ignorance of the precise nature of these objects safeguards our first choice - the choice of the game, that is, of the degree of violence. It is in this sense that Hume was able to write that it depended on us - which comes 
back to Immerwahr's interpretation. Nonetheless, it obeys the same passionate necessity as each of our choices - and this follows from Fogelin's interpretation.

\section{CONCLUSION}

Hume's writings provide three evaluative procedures for individual positions, the significance of which lies in the manner in which these are related.

- The decisional valuation as represented in [6] corresponds to an effective choice made in a context of choice S. The measure that is derived from this relates not to the sensation of pleasure, but to the force of the idea of pleasure. Typically, it leads to the discounting of future pleasure with respect to the degree of violence of the passion.

- The valuation of interest [12] can be understood as a fictional choice in a context S where the degree of violence $\mathrm{v}$ of the passions is given, under the assumptions where:

i. the concerned individual would have escaped the effects of the mechanism of belief formation, i.e. where he would not discount future pleasure since he would have the possibility of disregarding the difference between the sensation of pleasure and the force of the idea of pleasure;

ii. he would also disregard changes of preferences and of the capacity to experience pleasure engendered by the modifications to the degree of violence of the passions.

- The valuation of the greatest happiness represented in [14] opens the way to intraindividual comparisons by withdrawing the above hypothesis ii of the calculus of interest. As in the latter case, it corresponds to a fictional choice that abstracts from the effect of beliefs and does not discount future pleasure. But in taking account of the consequences of changes in the degree of violence of passions, it leads to a valuation of positions that will no longer correspond to one single stable passionate configuration, where choice is relative to the same context of choice $S$, subset of the same reference set of choice $X$ and to the same preference relation $\mathrm{R}$. On the contrary, the calculation of the greatest happiness allows a comparison of different stable passionate configurations. When the calculus of interest leads us to state that:

if I could, without taking into account the effect of my beliefs, succeed in varying the degree of violence of the passion animating me without altering my tastes and my sensitivity to pleasure, without the choices offered to me changing, here is what I will choose and which will give me the greatest pleasure; the calculus of happiness states:

if I could, always without taking into account the effect of my beliefs, succeed in varying the degree of violence of the passion animating me, then my tastes, my sensitivity to pleasure, and the choices offered to me would all change - and if moreover I were conscious of this, here is what I will choose and which will give me the greatest pleasure.

The relations between the two valuations, of interest and of happiness, appear then to be less rudimentary than a hasty reading of Hume's texts might suggest, a reading which would 
emphasise the proximity of interest and happiness. Admittedly, one suspects that happiness is distinguished from interest in that it potentially aims at another context of choice. But it is more fundamentally distinguished by the opening it gives for possible divergences in the same context of choice: the Treatise made possible an understanding that what we might desire does not necessarily conform to our interest; the second Enquiry revealed that what we desire was in general distinct from that which would have given us the greatest happiness; bringing together these two texts with the Essays shows that what answers our interest while our passions are not calm might also fail to coincide with our greater happiness.

This absence of coincidence, except precisely at this point where our passions became calm and where we would have achieved our greater happiness, seems for Hume to be an antidote to the limits of our cognitive and emotional capacities. We can always conceive the object which answers our interest, even if we do not pursue it: it is enough to imagine the realisation of our beliefs, whether weak or strong, without our tastes and without the context of our choices being fundamentally altered. Happiness, on the contrary, supposes changes which we can perhaps not even imagine, for this time they concern our tastes and the choices open to us. Interest becomes then an intermediate objective, recognisable and attainable, an operator in the transition to happiness. If indeed the evolution of our passions, circumstance or public policy favours our interest, our passions will be calmed, unleashing a passionate dynamics leading to our greater happiness. Even if it does not entirely carry conviction, there is a clear message in Hume's philosophical writings: don't we know what our happiness consists of? It is sufficient that our passions calm themselves and guide us towards our interest. This latter will lead us to happiness.

\section{REFERENCES}

Páll S. Árdal, 1966. Passion and Value in Hume’s Treatise, Edinburgh: Edinburgh University Press.

Jeremy Bentham, 1789. An Introduction to the Principles of Morals and Legislation, [1823 edition], New York: Hafner Press, 1948.

Jean-Pierre Cléro, 1985. La Philosophie des Passions chez David Hume, Paris: Klincksieck.

Francis W. Dauer, 1999. Force and Vivacity in the Treatise and the Enquiry, Hume Studies, 25(1/2), April and November, pp. 83-99.

Gordon F. Davis, 2003. Philosophical Psychology and Economic Psychology in David Hume and Adam Smith, History of Political Economy, 35(2), Summer, pp. 269-304.

Pierre Demeulenaere, 1996. Homo Economicus - Enquête sur la Constitution d'un Paradigme, Paris: Presses Universitaires de France.

Marc-Arthur Diaye et André Lapidus, 2005a. A Humean Theory of Choice of which Rationality May Be one Consequence, European Journal of the History of Economic Thought, 12(1), March, pp. 89-111. 
2005b. Why Rationality May Be a Consequence of Hume's Theory of Choice, European Journal of the History of Economic Thought, 12(1), March, 119-26.

James Fieser, 1992. Hume's Classification of the Passions and Its Precursors, Hume Studies, 18(1), April, pp. 1-17.

Robert J. Fogelin, 1985. Hume's Scepticism in the Treatise of Human Nature, London: Routledge and Kegan Paul.

David Hume, 1739-1740. A Treatise of Human Nature : Being an Attempt to Introduce the Experimental Method of Reasoning into Moral Subjects, edited by L.A. Selby-Bigge [1888] and P.H. Nidditch [1978], Oxford: Clarendon Press, 1978.

1740. An Abstract of a Treatise of Human Nature, in D. Hume, A Treatise of Human Nature, edited by L.A. Selby-Bigge [1888] and P.H. Nidditch [1978].

Enquiries Concerning Human Understanding and Concerning the Principles of Morals, edited by L.A. Selby-Bigge [1894, 1902] and P.H. Nidditch [1975], Oxford: Oxford University Press, 1975.

1748. Enquiry Concerning Human Understanding, in D. Hume, Enquiries, edited by L.A. Selby-Bigge [1894, 1902] and P.H. Nidditch [1975].

1751. Enquiry Concerning the Principles of Morals, in D. Hume, Enquiries, edited by L.A. Selby-Bigge [1894, 1902] and P.H. Nidditch [1975].

1757. A Dissertation on the Passions, in The Philosophical Works of David Hume, edited by T. H. Green and T. H. Grose, vol. IV, [London: 1882], Darmstadt: Scientia Verlag Aalen, 1964.

1777. Essays Political, Moral, and Literary, edited by E.F. Miller, Indianapolis: Liberty Classics, 1987. [The first date of publication or that of composition is given in brackets]

John Immerwahr, 1989. Hume's Essays on Happiness, Hume Studies, 15(2), November, pp. 307-24.

1992. Hume on Tranquillizing the Passions, Hume Studies, 18(2), November, pp. 293-314.

Norman Kemp Smith, 1941. The Philosophy of David Hume: A Critical Study of Its Origin and Central Doctrines, London: Macmillan, 1966.

André Lapidus, 2000. La Rationalité du Choix passionnel: En Quête de l'Héritage de David Hume, L'Année sociologique, 50(1), pp. 9-84.

Harold W. Noonan, 1999. Hume on Knowledge, London: Routledge.

Ignacio Palacios-Huerta, 2003. Time-Inconsistent Preferences in Adam Smith and David Hume, History of Political Economy, 35(2), Summer, pp. 241-68.

Robert Sugden, 2005. Why rationality is not a consequence of Hume's theory of choice, European Journal of the History of Economic Thought, 12(1), March, pp. 113-8.

Cass Weller, 2004. Scratched Fingers, Ruined Lives, and Acknowledged Lesser Goods, Hume Studies, 30(1), April, pp. 51-85.

Keywords: Hume, decision, welfare, desire, pleasure, belief, passion, intertemporal choice, utility, interest, happiness. 
JEL classification: B11, B31, D01, D60. 